\title{
Vascular Trauma Registry Analysis in Sulaimani Province of Southern Kurdistan
}

\author{
Aram Baram1,2*, Fahmi H. Kakamad3, Warzer F. Shali4, Rebwar Sayed-Nouri' ${ }^{5}$ \\ ${ }^{1}$ Department of Surgery, School of Medicine, Faculty of Medical Sciences, University of Sulaimani, \\ Sulaymaniyah, Iraq \\ ${ }^{2}$ Department of Thoracic and Cardiovascular Surgery, Sulaimani Teaching Hospital, Sulaymaniyah, Iraq \\ ${ }^{3}$ Department of Thoracic and Cardiovascular Surgery, School of Medicine, Faculty of Medical Sciences, \\ University of Sulaimani, Sulaymaniyah, Iraq \\ ${ }^{4}$ Department of Orthopedics and Trauma, Sulaimani DOH, Sulaymaniyah, Iraq \\ ${ }^{5}$ Department Cardiothoracic Surgery, Sulaimani DOH, Sulaymaniyah, Iraq \\ Email: aram.baramm@gmail.com
}

Received 25 June 2015; accepted 8 August 2015; published 11 August 2015

Copyright (C) 2015 by authors and Scientific Research Publishing Inc.

This work is licensed under the Creative Commons Attribution International License (CC BY).

http://creativecommons.org/licenses/by/4.0/

(c) (i) Open Access

\section{Abstract}

Background: Vascular injury presents a great challenge to the trauma and vascular surgeons because it needs urgent diagnosis and intervention. Aims: Prospective cohort study is to determine management and outcome of peripheral vascular injuries in a tertiary centre with very poor facilities. Methods: Analysis of peripheral vascular injuries during August 2013 to August 2014. Results: Total of 47 patients (3.4\%) from 1377 total trauma admissions had vascular injuries. Penetrating trauma was present in $93.6 \%$ of cases. Brachial artery injury was the highest $(31.9 \%)$, followed by superficial femoral and popliteal arteries (each with 17\% incidence). Vein injury occurred in $61.7 \%$ of cases. End-to-end anastomosis performed in 76.6\% of cases; arterial ligation was done in $14.9 \%$ of cases; venous graft was harvested in $6.4 \%$ of cases; and arterial wall was repaired in $2.1 \%$ of cases. Conclusions: Early intervention is the most important determinant factor of outcome.

\section{Keywords}

Peripheral Vascular Trauma, Hard Signs, Soft Signs, Long-Term Outcome, Surgical Effect, Complications

\footnotetext{
${ }^{*}$ Corresponding author.
} 


\section{Introduction}

Vascular injury is a major complication of military and civilian trauma [1]. It is one of the leading causes of mortality and morbidity worldwide and presents a great challenge to the emergency medical staff because these injuries require urgent intervention and also because sometimes serious vascular injury presents only with occult symptoms and signs [2] [3].

Because of the peripheral and more superficial location of these vessels clinical exam is very sensitive for diagnosis [4]. The 4 hard signs of extremity vascular injury include: pulsatile hemorrhage, palpable thrill or audible bruit, pulseless limb, and pulsatile expanding hematoma. When a patient presents with any of these 4 hard signs, immediate surgical exploration is warranted [5].

More difficult diagnostic problem occurs in patients who present with soft signs which include: history of severe hemorrhage, subjectively decreased or unequal pulses, nerve injury, non-pulsatile hematoma, and proximity [5].

Vascular injuries are often evaluated by invasive and non-invasive tests where there is a diagnostic dilemma. Non-invasive tests include: ankle brachial index measurement, hand held Doppler, B mode ultrasound, Duplex ultrasound, Color Flow Doppler ultrasound, and Magnetic Resonance Angiography (MRA). Invasive tests include conventional angiography and Digital Subtraction Angiography (DSA) [6].

In case of combined skeletal and vascular injuries, priority should be given to restoring blood supply to the extremity, but whether vascular repair should be definitive or temporized by way of intraluminal shunts is still debated at many centres [7].

In some cases, reperfusion worsens the damage caused by the initial ischaemia due to release of free oxygen radicals. This may be prevented by early revascularization [8]. Postoperative infection may cause secondary haemorrhage, thrombosis, ischemia and amputation. This is best avoided by vigorous cleansing of contaminated wounds, aggressive excision of devitalized tissue flaps and coverage of the repaired vessels with well vascularized soft tissue [9].

In this prospective cohort study, we want to determine management and outcome of peripheral vascular injuries in a single resource limited centre during a year.

\section{Patients and Method}

Patients with peripheral vascular injuries were followed prospectively during August, 2013 to August, 2014 during which 47 cases were diagnosed as vascular injured patients. A structured protocol was designed and filled in with variables such as patient's characteristics, signs and symptoms of vascular injury, mechanism of the trauma, anatomical locations, time to diagnosis and to definitive repair.

Informed written consent by explaining the nature of the procedure obtained from all the participants. The diagnosis of peripheral vascular injuries was mainly based on physical examination especially hard and soft signs, patients having any hard signs were taken to operation room for immediate exploration while those with soft signs were sent for Doppler ultrasound.

Specific surgical techniques were used to achieve successful vascular repair by the same surgical team. These include: proximal and distal exposure for control with vascular clamps and loops, dissection and isolation of injured vessels, and heparinization (systemic and local).

Techniques of repair included end-to-end anastomosis without tension with spatulation, and reversed autologous vein grafts were used for long arterial segment loss (Figure 1).

No any shunting procedure was used. Adjunct techniques were used whenever indicated as distal thrombectomy, fasciotomy and soft tissue coverage if required.

SPSS (Statistical Package for the Social Sciences version 20) package software program was used for statistical analysis.

\section{Results}

From total of 1377 causality admissions, 47 patients had vascular injuries (3.4\%). The male gender was $87.2 \%$ and the female was $12.8 \%$. The age range is 2 - 60 years, the mean age is 24.8 years. The mean time of interval between the accident and our intervention was 7.2 hours. The most common presentation was hypovolemic shock (Table 1). 


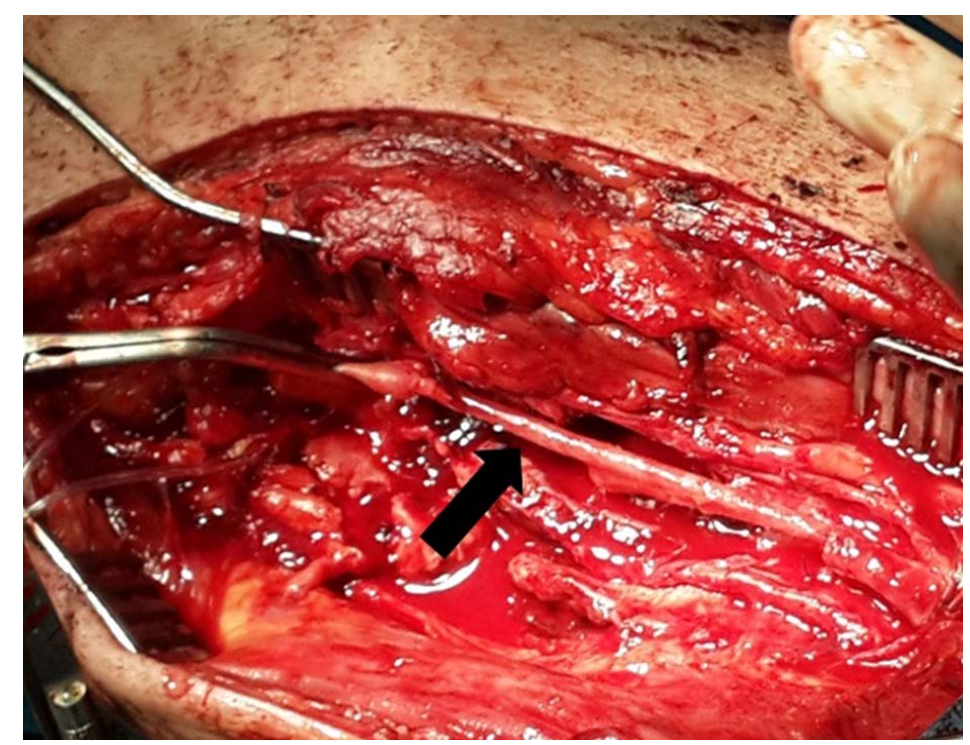

Figure 1. Reverse saphenous graft used for revascularization after bullet injury to left lower limb and segmental loss of the SFA of about $8 \mathrm{~cm}$ (arrow).

Table 1. Delay in the management and presentation.

\begin{tabular}{cccccc}
\hline Interval time and presentation & $\begin{array}{c}\text { Number } \\
\text { (patients) }\end{array}$ & $\begin{array}{c}\text { Minimum } \\
\text { (hours) }\end{array}$ & $\begin{array}{c}\text { Maximum } \\
\text { (hours) }\end{array}$ & $\begin{array}{c}\text { Mean } \\
\text { (hours) }\end{array}$ & Std. deviation \\
\hline Delay in the time from accident to definitive therapy & 47 & 3.00 & 20.00 & 7.2128 & 3.23659 \\
Hypovolemic shock pint of blood given & 47 & $\begin{array}{c}0.00 \text { pint of } \\
\text { blood }\end{array}$ & $\begin{array}{c}6.00 \text { pint of } \\
\text { blood }\end{array}$ & $\begin{array}{c}2.0000 \text { pint of } \\
\text { blood }\end{array}$ & 1.26834 \\
\hline
\end{tabular}

Vascular injuries caused by high velocity missile gunshot weapon (HVGSW) in 51\% of the cases, $21 \%$ caused by explosion, $14.9 \%$ by stab, $6.4 \%$ by blunt trauma.

Brachial artery was the higher incidence (31.9\%), followed by superficial femoral and popliteal injuries (17\%) later posterior tibial artery (12\%), axillary and common femoral arteries each with $6 \%$, radial artery was $4 \%$, subclavian artery was $2.1 \%$. Only $2.1 \%$ of case arteries were not affected (Table 2 ). These injuries associated with $61.7 \%$ vein injured, $55.3 \%$ nerve injured and $57.4 \%$ bone injury. Cardinal signs of ischemia (5Ps) found in $83 \%$ of cases, while in $17 \%$ of the cases the distal pulses were positive, about $83 \%$ of the cases had no profuse bleeding and only in $2.1 \%$ of the cases bruit was detected.

Revisualization by resection and end-to-end anastomosis performed in $76.6 \%, 14.9 \%$ of arteries were ligated, $6.4 \%$ of cases were managed with autologos reversed veins for lost segment more than $5 \mathrm{~cm}, 2.1 \%$ of arteries only ended with repaire of the torn wall. Fasciotomy was needed only for $12 \%$ of cases, $54.2 \%$ of veins were ligated, only $4 \%$ of veins were repaired. The rests (42.6\%) remained intact (Table 3 ).

During 3 - 6 months post-operative follow up, about $63.8 \%$ of cases, the limbs regained normal function and $23.4 \%$ of the cases, the limbs remained with reduced distal flow. Amputation was needed for $6.4 \%$ of the cases while $2.1 \%$ of the cases remained with neurological deficit. Arteriovenous (AV) fistula occurred in $2.1 \%$ of the cases and 2.1\% died post operatively after multi-organ failure (Table 4).

\section{Discussion}

Injuries to peripheral vessels have a potential to cause morbidity and mortality if they are not recognized and treated promptly [4]. In this series of patients vascular trauma occurred in 3.4\% of all civilian and military injuries, which is comparable with other studies by Farber et al. and Perkins et al. [2] [10]. In our series, we depended on physical examination (hard signs and soft signs) and Doppler US when the diagnosis was in question since the Doppler ultrasound is 95\% sensitive and 97\% specific in experienced hands [11].

Majority of the injuries were penetrating in nature, although we received civilian and military victims, nearly similar results were obtained in other studies [6] [11] [12]. 
Table 2. Distribution of arteries affected.

\begin{tabular}{ccc}
\hline Arteries & Frequency & Valid percent \\
\hline Brachial & 15 & 31.9 \\
Popliteal & 8 & 17.0 \\
Superficial femoral & 8 & 17.0 \\
Post tibial & 6 & 12.8 \\
Axillary & 3 & 6.4 \\
Common femoral & 3 & 6.4 \\
Radial & 2 & 4.3 \\
Subclavian & 1 & 2.1 \\
Artery not injured & 1 & 2.1 \\
Total & 47 & 100.0 \\
\hline
\end{tabular}

Table 3. Types of revascularization.

\begin{tabular}{ccc}
\hline Revascularization procedure & Frequency & Per-cent \\
\hline End-to-end & 36 & 76.6 \\
Ligation & 7 & 14.9 \\
Graft & 3 & 6.4 \\
Repair & 1 & 2.1 \\
Total & 47 & 100.0 \\
\hline
\end{tabular}

Table 4. Complications.

\begin{tabular}{ccc}
\hline Outcome & Frequency & Percent (\%) \\
\hline No late complication & 30 & 63.8 \\
Partial flow & 11 & 23.4 \\
Neurological deficit & 1 & 2.1 \\
Amputation & 3 & 6.4 \\
Arteriovenous fistula & 1 & 2.1 \\
Multi organ failure & 1 & 2.1 \\
Total & 47 & 100.0 \\
\hline
\end{tabular}

Brachial artery was most commonly affected (31.9\%) in our study, while others reported femoral and popliteal artery injuries as most common extremity vascular trauma [3] [12] [13]. This may be explained by cultural factors. However more studies with bigger sample size are necessary to provide more rational explanation for this variation from the international distribution.

The time lapse between injury and treatment is of critical importance for the outcome. Previous studies reported that 6 hours was the critical limit that determined the outcome [1] [13]. In our study 25 cases (53\%) arrived 6 hours after incidence of trauma. This may be due to absence of vascular specialist or inadequate facility in surrounding cities, since patients from those areas constitute large number of our sample ( $\mathrm{n}=33$ patients, $70 \%$ ). In our patient's group, almost all fasciotomy procedures, amputations and death occurred in patients who 
were revascularized after 6 hours following the injury.

Most patients present with multiple injuries and in these cases, a protocol based multidisciplinary team approach is essential to overcome theatre conflict. Orthopaedic fixation should be expedient to prevent undue prolongation of the ischemic time [11] [13]. When patient presented with complex injuries to the extremity, proximal and distal vascular control done, followed by orthopaedic intervention later on definitive vascular repair performed.

It is generally agreed that autologous vein grafts are the best due to durability, resistance to infection, and ability to draw nutrient flow from the surrounding viable tissues [9] [14]. Depending on these well known facts no prosthetic graft was used in our series while autologous vein grafts were used in 3 cases (6.4\%). Most authors agree that if there is a segmental loss of $2 \mathrm{cms}$ saphenous vein should be harvested from the contralateral limb to prevent an additional negative effect to the already compromised venous return [15]. We harvested greater saphenous vein from the affected limb to avoid involvement of the contralateral leg in the trauma, the graft flushed with heparinized saline and anastomosis done in a reversed way using parachute technique. After orthopaedic management, the graft was clinically reassessed to ensure the integrity of repair before reversal of anaesthesia. Graft failure varies among studies from zero to $36 \%$ [1] [16]. This may be seen due to vasospasm of the native artery and/or compartment syndrome [17]. We reported graft failure in one case and subsequent ischemia. No significant leg swelling observed within 6 months of follow up.

Venous repair remains a controversial issue in patients with vascular injuries [18]. However, most would agree that venous repair by means, other than simple lateral suturing and end-to-end anastomosis, is a time consuming process with uncertain benefits especially in multiply injured patients [14]. In our series, 2 out of 27 patients with venous injury underwent simple lateral repair, others underwent ligation. There was no significant squeale following vein ligation other than mild oedema which was relieved during discharge. This finding is consistent with other studies [19].

There is controversy about the timing of fasciotomy and the role of intra-compartmental pressure measurement. According to other studies, the location of the arterial injury is the main determinant of fasciotomy in patients with lower extremity vascular injuries [20]. In our study, fasciotomy was performed in six patients (12.8\%) judged by time of ischemia and clinical findings during operation like calf muscle tenseness and failure of peripheral pulses to return back after revascularization.

The complication rate in emergency revascularization has been reported in different studies to be between 10 and $18 \%$ [4]. In our study, $10.6 \%$ of the patients developed various complications (amputation, fistulas and death). Limb ischemia occurred after revascularization in one patient (2.1\%) which is comparable with other studies [14].

The decision for limb amputation is more difficult than it seems. Sometimes, early amputation can be the best option for some patients that saves their lives. Amputation rate depends on many factors including the severity of limb injury, mechanism of injury, ischemia time, and presence of associated injuries [14]. In our study 3 patients (6.4\%) underwent amputation as a result of severe infection causing anastomotic disruption and impending septicaemia. This finding is comparable with other reports [3] [9].

\section{Conclusions}

Vascular injuries remain a challenge to the trauma surgeon. Early diagnosis and treatment is crucial for saving the patient's limb and life. In spite of increasing availability and advances in imaging technology, physical examination (hard signs and soft signs) remains easiest and most sensitive way for diagnosis of peripheral vascular injuries.

Harvesting saphenous vein graft from ipsilateral leg can be safe and avoid involvement of the contralateral leg to the trauma. However more studies are recommended to provide higher level of evidence.

\section{Acknowledgements}

We would like to acknowledge all our personnel who assisted in serving our patients.

\section{Conflict of Interest}

Non to be declared. 


\section{Author's Contribution}

Aram Baram: surgeon performed the surgeries, study design, follow-up, data collection, statistical analysis. Warzer F. Shali: study design, follow-up, data collection, statistical analysis.

Fahmi H. Kakamad: study design, follow-up, data collection, statistical analysis.

Rebwar Sayd-Nouri: study design, follow-up, data collection, statistical analysis.

\section{Funding}

This research received no specific grant from any funding agency in the public, commercial, or not-for-profit sectors.

\section{References}

[1] Shalabi, R., Al Amri, Y. and Khoujah, E. (2006) Vascular Injuries of the Upper Extremity. Jornal Vascular Brasileiro, 5, 271-276. http://dx.doi.org/10.1590/S1677-54492006000400006

[2] Perkins, Z.B., De’Ath, H.D., Aylwin, C., Brohi, K., Walsh, M. and Tai, N.R.M. (2012) Epidemiology and Outcome of Vascular Trauma at a British Major Trauma Centre. European Journal of Vascular and Endovascular Surgery, 44, 203-209. http://dx.doi.org/10.1016/j.ejvs.2012.05.013

[3] Wani, M.L., Ahangar, A.G., Wani, S.N., Dar, A.M., Ganie, F.A., Singh, S., Lone, R.A. and Wani, N. (2012) Peripheral Vascular Injuries Due to Blunt Trauma (Road Traffic Accident): Management and Outcome. International Journal of Surgery, 10, 560-562. http://dx.doi.org/10.1016/j.ijsu.2012.08.018

[4] Murad, M., Eweda, A., Abdel-Moamen, H., Hussien, M. and Elsaghir, M. (2013) Vascular Trauma and Its Management: One and a Half Years after the 25th January Revolution. Journal of the Arab Society for Medical Research, 8, 43-47.

[5] Levy, B.A., Zlowodzki, M.P., Graves, M. and Cole, P.A. (2005) Screening for Extermity Arterial Injury with the Arterial Pressure Index. American Journal of Emergency Medicine, 23, 689-695. http://dx.doi.org/10.1016/j.ajem.2004.12.013

[6] Wani, M.L., Sheikh, M.T., Ul-Hassan, N., Irshad, I., Ahangar, A.G., Ganie, F.A., Sheikh, M.T. and Wani, S.N. (2014) Evaluating Peripheral Vascular Injuries: Is Color Doppler Enough for Diagnosis? International Cardivascular Research Journal, 8, 15-17.

[7] Desai, P., Audige, L. and Suk, M. (2012) Combined Orthopedic and Vascular Lower Extremity Injuries: Sequence of Care and Outcomes. American Journal of Orthopedics, 41, 182-186.

[8] Percival, J. and Rasmussen, T.E. (2012) Reperfusion Strategies in the Management of Extremity Vascular Injury with Ischaemia. British Journal of Surgery, 99, 66-74. http://dx.doi.org/10.1002/bjs.7790

[9] Krüger, A., et al. (2013) Penetrating Arterial Trauma to the Limbs: Outcome of a Modified Protocol. World Journal of Emergency Surgery, 8, 51. http://dx.doi.org/10.1186/1749-7922-8-51

[10] Farber, A., et al. (2012) Early Fasciotomy in Patients with Extremity Vascular Injury Is Associated with Decreased Risk of Adverse Limb Outcomes: A Review of the National Trauma Data Bank. Injury, 43, 1486-1491. http://dx.doi.org/10.1016/j.injury.2011.06.006

[11] Jawas, A., Hammad, F., Eid, H.O. and Abu-Zidan, F.M. (2010) Vascular Injuries Following Road Traffic Collisions in a High-Income Developing Country: A Prospective Cohort Study. World Journal of Emergency Surgery, 5, 13. http://dx.doi.org/10.1186/1749-7922-5-13

[12] Oliver, J.C., Gill, H., Nicol, A.J., Edu, S. and Navsaria, P.H. (2013) Temporary Vascular Shunting in Vascular Trauma: A 10-Year Review from a Civilian Trauma Centre. The South African Journal of Surgery, 51, 6-10.

[13] Sada, U., Kullar, P.J., Noorani, A., Gillard, J.H., Coope, D.G. and Boyle, J.R. (2008) Emergency Endovascular Management of Peripheral Artery Aneurysms and Pseudoaneurysms-A Review. World Journal of Emergency Surgery, 3, 22. http://dx.doi.org/10.1186/1749-7922-3-22

[14] Wani, M.L., Ahangar, A.G., Ganie, F.A., Wani, S.N. and Wani, N. (2012) Vascular Injuries: Trends in Management. Trauma Monthly, 17, 266-269. http://dx.doi.org/10.5812/traumamon.6238

[15] Shi, L. (2013) The Delayed Management of Main Arterial Injuries in Extremity Trauma: Surgical Challenges and Outcomes. Pakistan Journal of Medical Sciences, 29, 64-67.

[16] Topal, A.E., Eren, M.N. and Celik, Y. (2010) Lower Extremity Arterial Injuries over a Six-Year Period: Outcomes, Risk Factors, and Management. Vascular Health and Risk Management, 6, 1103-1110. http://dx.doi.org/10.2147/VHRM.S15316 
[17] Timberlake, G.A. and Kerstein, M.D. (1995) Venous Injury: to Repair or Ligate, the Dilemma Revisited. The American Surgeon, 61, 139-145.

[18] Yelon, J.A. and Scalea, T.M. (1992) Venous Injuries of the Lower Extremities and Pelvis: Repair versus Ligation. The Journal of Trauma, 33, 532-538. http://dx.doi.org/10.1097/00005373-199210000-00008

[19] Rasouli, M.R., Moini, M., Khaji, A., Heidari, P. and Anvari, A. (2010) Traumatic Vascular Injuries of the Lower Extremity: Report of the Iranian National Trauma Project. Turkish Journal of Trauma \& Emergency Surgery, 16, 308312.

[20] de Silva, W.D.D., Ubayasiri, R.A., Weerasinghe, C.W. and Wijeyaratne, S.M. (2011) Challenges in the Management of Extremity Vascular Injuries: A Wartime Experience from a Tertiary Centre in Sri Lanka. World Journal of Emergency Surgery, 6, 24. http://dx.doi.org/10.1186/1749-7922-6-24 